\title{
ESTUDO DE ILHAS DE CALOR NO MUNICÍPIO DE PIRATININGA/SP, POR MEIO DE DADOS ORBITAIS DO LANDSAT 5 SENSOR TM ${ }^{1}$
}

\author{
Nathalia Maria Salvadeo Fernandes Parizoto $^{2}$ \& Sérgio Campos 3 \\ RESUMO: Com a ocupação massiva da malha urbana e as atividades decorrentes do crescimento desordenado dessas \\ áreas, ocorre uma alteração do clima urbano, tornando-o insalubre. Um dos fatores que contribui para a má qualidade de \\ vida em decorrência deste fato são as ilhas de calor que consiste no acúmulo de calor na superfície e eleva a temperatura \\ nas cidades. A vegetação urbana constituída de arborização urbana, bosques e áreas verdes, têm como função minimizar \\ este efeito. Para conciliar esses fatores o trabalho tem como objetivo levantar os dados de temperatura de superfície \\ através de imagens de satélite, LANDSAT 5 captada no dia 18/12/2012 dos pontos 75 e 76, órbita 221, banda 6 e \\ levantamento in loco com termo-higrômetro, com posse dos dados, cruzar com o levantamento vegetativo realizado e \\ proporcionar uma visão de gestão para melhorar o microclima do município em estudo. A cobertura de vegetação na \\ área urbana interfere diretamente na diminuição da temperatura melhorando o micro-clima urbano. As diferentes \\ coberturas da superfície analisada também interferem na temperatura aparente. Entre as classes estudas a classe cultivo \\ de eucalipto, mata nativa, área urbana e solo exposto, as áreas com maior cobertura vegetal apresentam uma \\ temperatura amena e uma melhoria no micro-clima.
}

PALAVRAS-CHAVE: Ilhas de calor, geoprocessamento, arborização urbana, gestão pública.

\section{Study Of Head Island In The City Of Piratininga-SP Using Orbital Data From The Landsat 5 Sensor TM}

\begin{abstract}
The massive urbanization and activities arising from the uncontrolled growth of urban areas, result in changes on the climate, making it unhealthy. One factor that contributes to poor quality of life due to this fact is the islands of heat that consists in the accumulation of surface heat and raises the temperature in the cities. The vegetation consists of urban greening, urban forests and green areas, have the function to minimize this effect. To reconcile these factors, collected data on surface temperature by satellite images, LANDSAT 5 captured on 18/12/2012 point 75 e 76, orbits 221, band 6 and on-site survey with thermo-hygrometer, possessed the data, crossing the conducted vegetative survey and provided a management vision to improve the microclimate of the city under study. The vegetation coverage at urban area directly affects the ambient temperature, improving the urban micro-climate. The different analyzed surface coverage also affects the apparent temperature. Among the studied ranks, the eucalyptus cultivation, native forest, urban area and solo exposed areas with greater vegetation cover have mild temperatures and improved microclimate.
\end{abstract}

KEYWORDS: Heat islands, geoprocessing, urban forestry; public management.

\section{INTRODUÇÃO}

Segundo a Organização das Nações Unidas (ONU) hoje a população mundial soma 7,2 bilhões/ano de pessoas, sendo que mais de $50 \%$ encontra-se locado em área urbana. As atividades decorrentes do crescimento urbano e industrial descontrolado ocasionam um ambiente insalubre nas cidades, devido às alterações na pureza do

\footnotetext{
${ }^{1}$ Parte da dissertação de mestrado do $1^{\circ}$ autor intitulada: ESTUDO DE ILHAS DE CALOR NO MUNICÍPIO DE PIRATININGA/SP, POR MEIO DE DADOS ORBITAIS DO LANDSAT 5 SENSOR TM.. Defesa: 19/12/2013.

${ }^{2}$ Faculdade de Ciências Agronômicas, Universidade Estadual Paulista FCA/UNESP, Departamento de Engenharia Rural.E-mail: nasalvalia@gmail.com

${ }^{3}$ Orientador e docente da Faculdade de Ciências Agronômicas, Universidade Estadual Paulista - FCA/UNESP, Departamento de Engenharia Rural. E-mail: seca@fca.unesp.br
}

ar e climáticas. Assim, os benefícios ambientais da arborização se tornam mais necessários à saúde ambiental do ecossistema urbano, quanto maior o nível de urbanização.

A vegetação nas cidades surge normalmente como jardins e parques, ocupando diferentes áreas com aspectos e função variada (ALMEIDA, 2006).

A arborização urbana bem como as áreas cobertas por vegetação (floresta urbana) contribui não apenas para a melhoria do Clima, mas também para o controle da poluição atmosférica filtrando partículas, retendo poeira e fumaça e proporcionando conforto acústico em alguns casos. No entanto varias cidades brasileiras não possuem 
adequado planejamento de arborização urbana não atingindo assim o seu fundamento (ALMEIDA, 2009)

Atualmente com o avanço das geotecnologias e dos dados de sensoriamento remoto, como o aumento da resolução de imagens de satélite, obtém-se diversas informações do ambiente terrestre. Uma das informações contidas nas imagens é a temperatura aparente da superfície, através da captação da energia eletromagnética emitida por determinado ambiente ou objeto.

A tecnologia junto com os avanços em geoprocessamento fornece ao poder público novos horizontes de gestão, com a utilização de imagens de satélite e levantamento de campo é possível organizar e distribuir a arborização urbana, áreas verdes e praças de forma a propiciar um ambiente com temperaturas agradáveis, alem de outros benefícios que acompanham a linha de benefícios.

Além da rápida obtenção de dados e disponibilidade gratuitas das imagens de satélite, o uso do sensoriamento remoto é crescente devido aos registros históricos disponíveis, oferecendo dados importantes para a análise temporal do desenvolvimento das ilhas de calor.

Os Sistemas de Informação Geográficos (SIG) são ferramentas fundamentais para aplicação das técnicas de processamento digital das imagens, possuem diversos algoritmos e dentre eles um capaz de transformar os dados do infravermelho termal que permitiu obter a temperatura aparente da superfície, imprescindíveis para interpretação destes dados.

O objetivo deste trabalho é utilizar o sensoriamento remoto e a imagem de satélite para avaliar a temperatura confrontando a existência de ilhas de calor e arborização urbana, utilizando imagens de satélite e levantamento de arborização urbana realizado anteriormente, a fim de auxiliar na gestão de uso do solo urbano visando a melhoraria do micro-clima.

\section{MATERIAL E MÉTODOS}

\section{MATERIAL E MÉTODOS}

O Município de Piratininga está situado a noroeste do Estado de São Paulo, na latitude sul 22 24' $02^{\prime \prime}$ e longitude oeste de Greenwich 4908'00".

O Município localiza-se próximo as rodovias Marechal Rondon (SP 300) e Comandante João Ribeiro de Barros (SP 294). Com território de $392 \mathrm{Km}^{2}$, limita-se com os municípios de Bauru (Norte e Nordeste), de Agudos (Sul e Sudeste), de Duartina (Noroeste), de Cabrália Paulista (Oeste) e de Avaí (Norte e Noroeste), como demonstrado na Figura 1.

A classificação climática geral, segundo Koeppen, é Aw, mais quentes, tropical chuvoso com inverno seco e mês mais frio com temperatura média superior a $18^{\circ} \mathrm{C}$ e o solo Latossolo Vermelho (CEPAGRI, 2013), não havendo até momento estudos climáticos específicos.

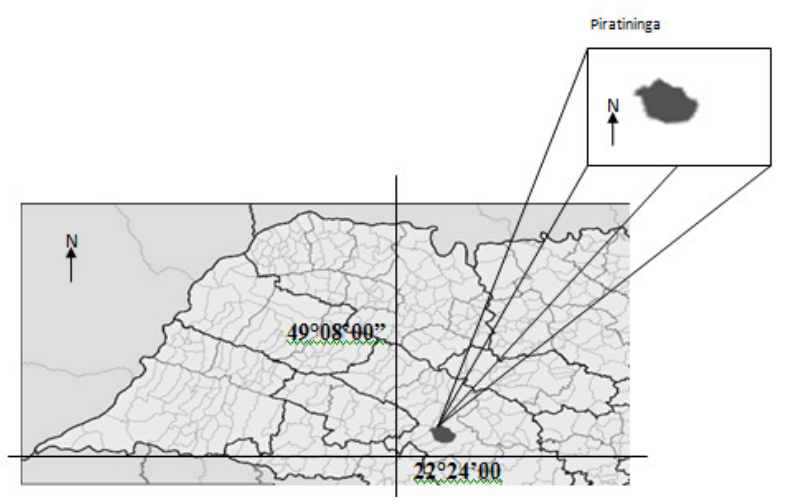

Figura 1 - Localização do Município de Piratininga.

A temperatura média anual é de $22,2^{\circ} \mathrm{C}$ com Max. de $30,6^{\circ} \mathrm{C}$ e min. $11,3^{\circ} \mathrm{C}$ e a precipitação anual é de aproximadamente $1.317,1 \mathrm{~mm}$. (CEPAGRI, 2013)

A densidade demográfica de Piratininga, em 1996, conforme dados do IBGE, era de $25,7 \mathrm{hab} / \mathrm{km}^{2}$, cabendo à zona urbana $81,7 \%$ do total de habitantes, e apenas $18,3 \%$, para a zona rural, o senso realizado em 2010 apresentou população estimada de 12.072 habitantes, um aumento de $30 \mathrm{hab} / \mathrm{km} 2$ de densidade demográfica.

Foram utilizados os programas, Idrisi 15.0 - Andes Edition, desenvolvido pelo Clark Labs@ for Cartographic Technology and Analysis como programa de sistemas de informação geográfica e o AutoCad para vetorização dos dados e o Google earth $\bigodot$ para criação dos polígonos dos setores.

Para obtenção da temperatura foram utilizados dados vetoriais da malha urbana e da delimitação de cada bairro do município que foram confeccionados no programa Autocad Map, usando-se como base a imagem do satélite Landsat 5, com foco na banda 6 infravermelho.

As fases de pré-processamento, processamento e transformação dos níveis de cinza em temperatura aparente foram executados no programa de Sistema de Informação Geográfica (SIG) Idrisi 15.0 - Andes Edition.

As imagens utilizadas do sensor TM (Thematic Mappper) a bordo no satélite Landsat 5. A banda 6 do infravermelho termal, para obtenção da temperatura de superfície. Todas as imagens correspondem à órbita 221 ponto 075 e 076.

As imagens foram adquiridas através da página de catálogo de imagens do Instituto de Pesquisas Espacias (INPE), referente às seguintes datas: 18/12/2012. As imagens foram escolhidas na estação correspondente a primavera, após um longo período de estiagem. 
Os dados de arborização urbana e áreas verdes foram adquiridos através de mapa do município de Piratininga através da Prefeitura Municipal em levantamento realizado anteriormente. (FERNANDES, et al. 2011)

Para a obtenção dos dados da temperatura aparente da superfície é necessário o pré-processamento das imagens. Primeiramente a cena foi reduzida de modo a restringir-se apenas à área de estudo, utilizando-se a ferramenta reformat menu (WINDOW) do Idrisi. Após a redução, foi aplicado o realce com o intuito de melhorar a qualidade visual das imagens. $\mathrm{O}$ município em estudo está representado em duas cenas de pontos diferentes da mesma órbita o que leva ao processamento de imagem através da opção mosaico.

Para correção dos erros contidos na imagem devido à movimentação do satélite e curvatura da Terra (projeção e sistema de referência) foi executada a retificação geométrica.

O algorítimo de transformação do DN (número digital) para graus Celsius utilizado foi do programa Idrisi 15.0, devidamente validada por Coltri (2006), através das funções Image processing (TRANSFORMATION/ THERMAL).

Para encontrar as faixas intermediárias de níveis de cinza de cada imagem, foi feito um histograma a imagem.

Os valores de temperatura das imagens foram submetidos a análise de variância a fim de verificar se os valores encontrados se diferem estatisticamente, caso sejam diferentes serão submetidos ao teste de Tukey, ao nível de 5\% para comparação de médias duas a duas.

O mapa de áreas verdes e arborização urbana, no formato, Dwg (desing web format, extensão de arquivo de desenho em 2D ou 3D), permitiu o cruzamento de informações de temperatura e as áreas verdes com o objetivo de verificar se há influência de mudança do micro-clima relacionado entre essas áreas.

O levantamento de temperatura no município utilizandose o thermohigrômetro Smart Sensor® modelo AR 837, realizado no dia 21/11/2012 com início as $14 \mathrm{~h} 30$ e término as $15 \mathrm{~h} 32$, que mostra as temperaturas mínimas e máximas $\left({ }^{\circ} \mathrm{C}\right)$ além da máxima umidade relativa do ar (\%) de 25 pontos distintos.

Os pontos foram escolhidos aleatoriamente em vários locais da cidade distantes entre si e atingiu toda a malha urbana.

A área do município foi classificada de acordo com o uso do solo, por meio de imagens de satélite obtidas pelo Google Earth.

Foram identificados 4 tipos de classe de interesse: Cultura de Eucalipto, Mata nativa, Área urbana e Solo exposto.
A malha urbana do município foi dividida por setores, representado na Figura 2, tendo em vista os limites de bairros já conhecidos. Alguns bairros são relativamente pequenos, o que permitiu uni-los formando um único setor, conforme mostrado na Tabela 1.

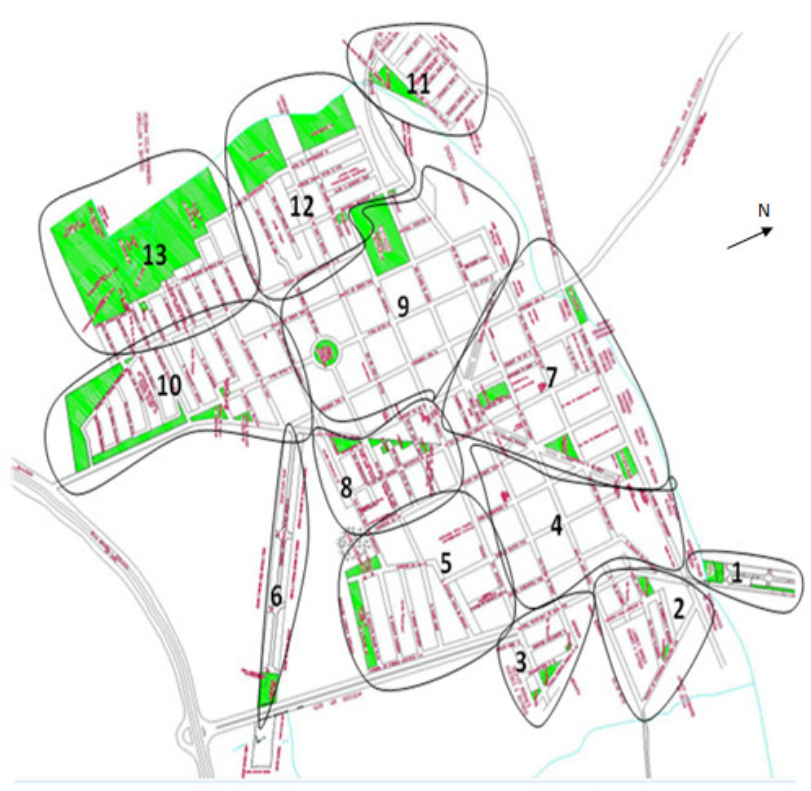

Figura 2 - Mapa de setorização.

Tabela 1 - Setores do Município de Piratininga.

\begin{tabular}{|c|c|}
\hline SETOR & BAIRRO \\
\hline 1 & Parque Bela Vista \\
\hline 2 & Vila Soares \\
\hline 3 & Vila Moraes \\
\hline 4 & Centro I \\
\hline 5 & Jardim Panorama \\
\hline 6 & Jardim Santo Antônio \\
\hline 7 & Jd. Ferroviário Pta. I, II, III e Centro II \\
\hline 8 & $\begin{array}{l}\text { Jd. Cel. Antonio da Cunha Castro, Jd } \\
\text { Panorama II e Conj. Hab. "Padre Unsué } \\
\text { Verde" }\end{array}$ \\
\hline 9 & Centro III \\
\hline 10 & $\begin{array}{l}\text { Jd. Kirilos, Conj. Hab. "Dr. Antônio Ferreira } \\
\text { do Espírito Santo" }\end{array}$ \\
\hline 11 & $\begin{array}{l}\text { Conj. Hab. "Luis Faustino de Souza", Boa } \\
\text { Vista I, II, III e IV e Conj. Hab. "Sebastiana } \\
\text { Garcia Falqueiro" }\end{array}$ \\
\hline 12 & Coj. Hab. “Amire Maluf” e Jardim Vilane \\
\hline 13 & $\begin{array}{l}\text { Conj. Hab. "Fernando Motta Mendes" e Jd. } \\
\text { Santa Maria }\end{array}$ \\
\hline
\end{tabular}

A temperatura aparente da superfície foi levantada em campo através de um termo-higrômetro e pela banda 6 de uma imagem de satélite no dia 18/12/2012. Esses dados serão analisados a fim de sobrepor informações de áreas verdes, arborização urbana e ilhas de calor proporcionando assim a possibilidade de análise da atual situação e interferência desses dados na qualidade de vida da população.

\section{RESULTADOS E DISCUSSÃO}

Após a aplicação do algoritmo termal de transformação e processamento da imagem, obteve-se o comportamento 
da temperatura aparente do município de Piratininga do dia 18/12/2012, conforme representado na Figura 3.

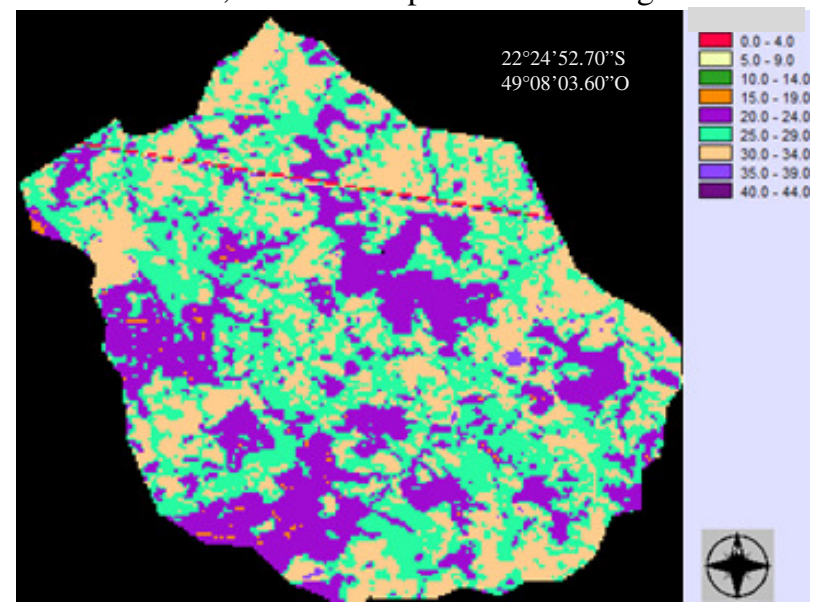

Figura 3 - Temperatura aparente da superfície do Município de Piratininga.

Foram identificadas 10 faixas de temperatura que variaram de $0.0^{\circ} \mathrm{C}$ a aproximadamente $44.0^{\circ} \mathrm{C}$. As temperaturas de $0.0^{\circ} \mathrm{C}$ a $4.0^{\circ} \mathrm{C}$ representado pela cor pink foi registrada devido ao ruído (falha na imagem) resultante do processo de junção das imagens (mosaico). No detalhe, a Figura 4 mostra a faixa de temperatura nos setores anteriormente definidos da área urbana, sobreposta á imagem da área, é possível observar que as temperaturas variam de $20^{\circ} \mathrm{C}$ (lilás) a $34^{\circ} \mathrm{C}$ (bege).

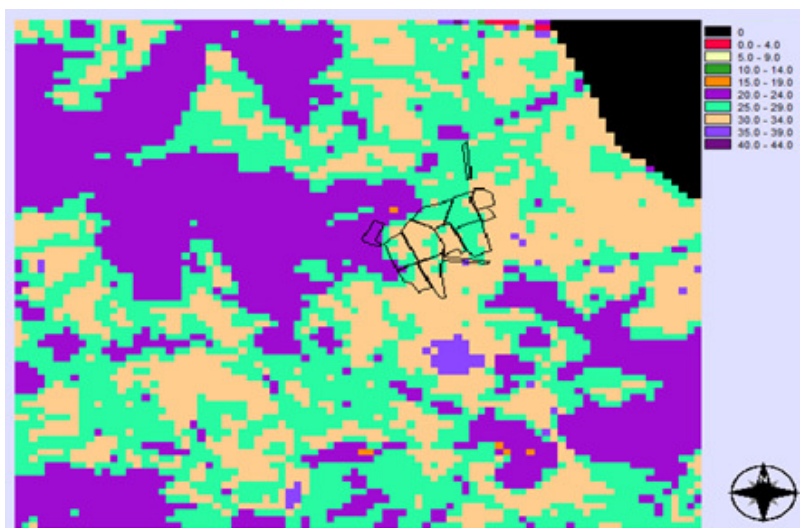

Figura 4 - Polígono dos setores da área urbana do município.

Pôde se identificar quatro classes representadas na Figura 5 e referenciadas na Tabela 2.

\section{Tabela 2 - Coordenadas das classes de solo}

\begin{tabular}{|c|c|c|c|}
\hline Ponto & Coordenada $x$ & Coordenada y & Classe \\
\hline 1 & $22^{\circ} 24^{\prime} 50^{\prime \prime}$ & $49^{\circ} 08^{\prime} 08^{\prime \prime}$ & Área urbana \\
\hline 2 & $22^{\circ} 25^{\prime} 11^{\prime \prime}$ & $49^{\circ} 08^{\prime} 47^{\prime \prime}$ & $\begin{array}{l}\text { Cultura de } \\
\text { eucalipto }\end{array}$ \\
\hline 3 & $22^{\circ} 25^{\prime} 38^{\prime \prime}$ & $49^{\circ} 09^{\prime} 44^{\prime \prime}$ & Mata nativa \\
\hline 4 & $22^{\circ} 24^{\prime} 55^{\prime \prime}$ & $49^{\circ} 07^{\prime} 22^{\prime \prime}$ & Solo exposto \\
\hline
\end{tabular}

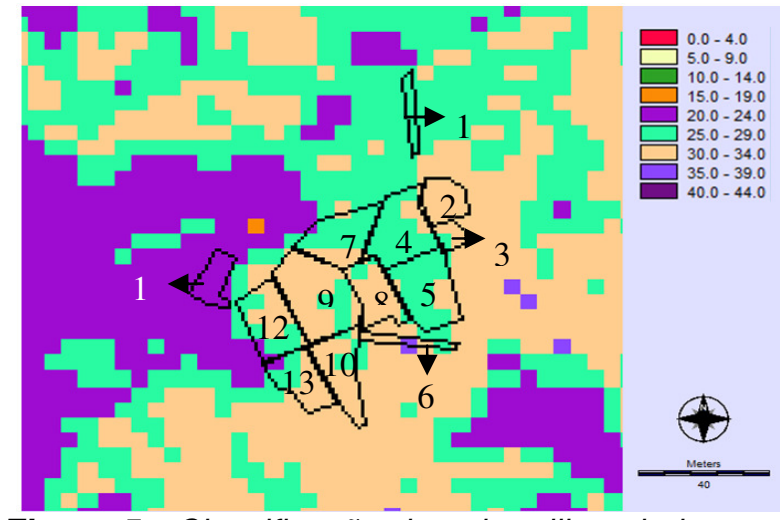

Figura 5 - Classificação do solo utilizando imagem do Google.

Devido às diferentes épocas de ocupação do espaço urbano, é possível trabalhar por setores e detectar diferenças de temperatura resultante do tipo de edificação e intensidade de impermeabilização do solo.

Os setores 4, 5 e 7 são mais antigos e apresentam temperaturas em torno de $25.0^{\circ} \mathrm{C}$ a $29.0^{\circ} \mathrm{C}$ (Figura 6) esse padrão de temperatura é devido a arborização urbana, constituída de espécies arbóreas de grande porte com Índice de Cobertura Vegetal correspondente a metade do tamanho de área impermeável, como indicado na Tabela 3.

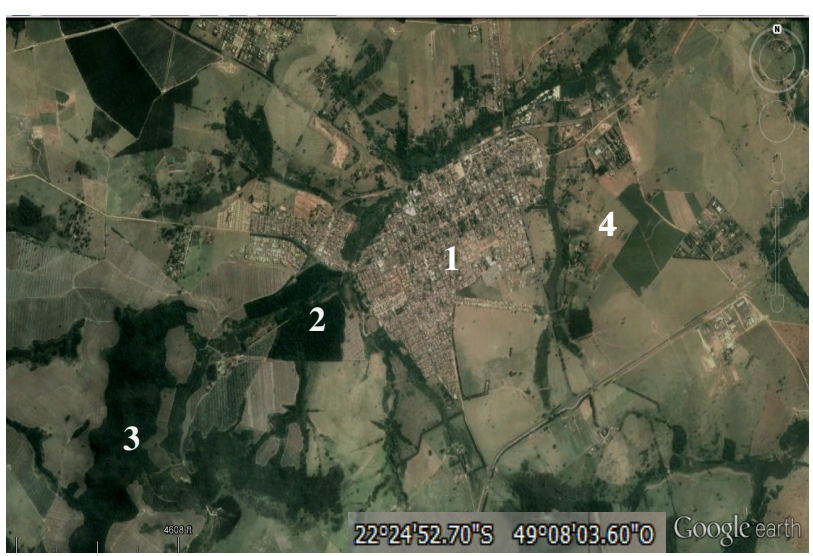

Figura 6 - Detalhe da temperatura aparente da área urbana.

Tabela 3 - Índice de cobertura vegetal.

\begin{tabular}{ccc}
\hline Setor & $\mathbf{I C V}\left(\mathbf{m}^{2}\right)$ & \% \\
\hline $\mathbf{4}$ & $56.130,769$ & 38,35 \\
$\mathbf{5}$ & $29.619,031$ & 33,82 \\
$\mathbf{7}$ & $29.619,031$ & 41,70 \\
\hline
\end{tabular}

\section{ICV: Índice de Cobertura Vegetal}

Fonte: Fernandes, 2011.

O setor 1 também apresenta temperatura variável entre $25.0^{\circ} \mathrm{C}$ a $29.0^{\circ} \mathrm{C}$ este caso ao contrário dos anteriormente citados é um bairro novo, porém sua área de cobertura vegetal é maior, segundo Fernandes et al (2011), pois muitos terrenos ainda não estão edificados e a população ainda é reduzida.

Analisando os setores 9, 10, 12 e 13 (Figura 6), podemos observar que a predominância é de temperaturas mais 
elevadas que estão entre $30.0^{\circ} \mathrm{C}$ a $34.0^{\circ} \mathrm{C}$. Isso ocorre devido ao grande número populacional da região que é ocupado em sua maior parte por moradia social. Os pontos de temperatura variável entre $25.0^{\circ} \mathrm{C}$ a $29.0^{\circ} \mathrm{C}$ dos mesmos setores ocorre devido a uma concentração da arborização representada por praças e áreas verdes.

A temperatura amena no setor 11 é devido a proximidade do plantio de eucalipto que ladeia todo o loteamento e por ser um bairro periférico, apresenta uma diferença de temperatura, como descrito por Lombardo (1985).

Os setores 4, 5 e 7 apresentam uma média de temperatura de $27,0^{\circ} \mathrm{C}$ sendo os setores com temperatura mais amena devido a área de cobertura vegetal.

A diferença de temperatura nos setores 9, 10, 12 e 13 de $32.0^{\circ} \mathrm{C}$ para $27.0^{\circ} \mathrm{C}$ é devido a existência de áreas verdes como praças.

O levantamento em campo foi realizado com pontos aleatórios demonstrados na Figura 7 como mostra a variação de temperatura em torno de $34,4^{\circ} \mathrm{C}$ a $36,6^{\circ} \mathrm{C}$, demonstrado na tabela 4 .

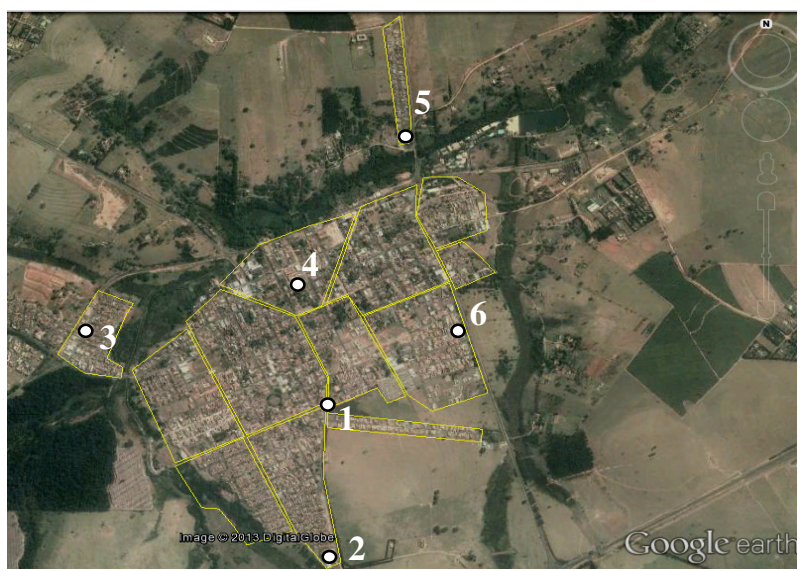

Figura 7 - Pontos de localização do levantamento de temperatura em campo.

Tabela 4 - Levantamento com termo-higrômetro 21/11/2012.

\begin{tabular}{cccc}
\hline Ponto & $\begin{array}{c}\text { Coordenada } \\
\mathrm{X}\end{array}$ & $\begin{array}{c}\text { Coordenada } \\
\text { Y }\end{array}$ & $\begin{array}{c}\text { Temperatura } \\
\left({ }^{\circ} \mathrm{C}\right)\end{array}$ \\
\hline 1 & $22^{\circ} 25^{\prime} 02^{\prime \prime}$ & $49^{\circ} 08^{\prime} 05^{\prime}$ & 34,4 \\
2 & $22^{\circ} 25^{\prime} 26^{\prime \prime}$ & $49^{\circ} 08^{\prime} 04^{\prime \prime}$ & 35,6 \\
3 & $22^{\circ} 24^{\prime} 49^{\prime \prime}$ & $49^{\circ} 08^{\prime} 44^{\prime \prime}$ & 36,8 \\
4 & $22^{\circ} 24^{\prime} 43^{\prime \prime}$ & $49^{\circ} 08^{\prime} 09^{\prime}$ & 35,8 \\
5 & $22^{\circ} 24^{\prime} 19^{\prime \prime}$ & $49^{\circ} 07^{\prime} 51^{\prime \prime}$ & 35,2 \\
6 & $22^{\circ} 25^{\prime} 50^{\prime \prime}$ & $49^{\circ} 08^{\prime} 43^{\prime \prime}$ & 36,6 \\
\hline
\end{tabular}

Na figura 8 podemos observar uma mancha na cor lilás com temperatura variável entre $20.0^{\circ} \mathrm{C}$ a $24.0^{\circ} \mathrm{C}$, essa área corresponde ao cultivo de eucalipto, a temperatura amena é devido a utilização da incidência da luz solar $\mathrm{Na}$ figura 8 podemos observar uma mancha na cor lilás com temperatura variável entre $20.0^{\circ} \mathrm{C}$ a $24.0^{\circ} \mathrm{C}$, essa área corresponde ao cultivo de eucalipto, a temperatura amena é devido a utilização da incidência da luz solar pelas folhas nos processos biológicos como, por exemplo, a fotossíntese.

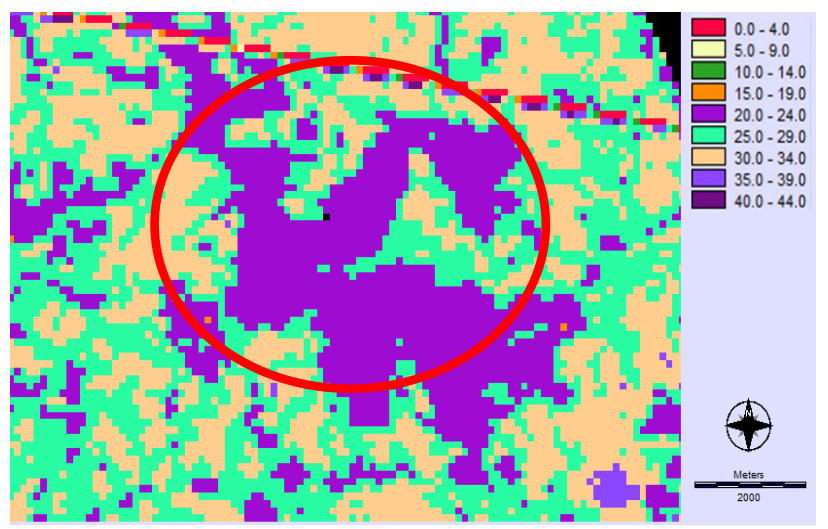

Figura 8 - Classe Cultivo de Eucalipto.

A área de mata nativa representada pela cor lilás, na Figura 9, se mistura com a vegetação de cultivo de eucalipto por estarem próximas e apresentarem a mesma temperatura aparente. Essa igualdade de temperatura se deve a homogeneidade da vegetação que se encontra em estado tardio de regeneração, estando com o desempenho físico-químico em total desempenho há um maior aproveitamento da incidência de radiação solar, bem como na cultura de eucalipto que possui plantio uniforme e de mesma idade.

Outra análise que pôde ser feita na Figura 9 permite observar que existe uma transição entre as áreas de temperaturas amenas e elevadas como se fosse um cinturão de forma a mesclar as temperaturas.

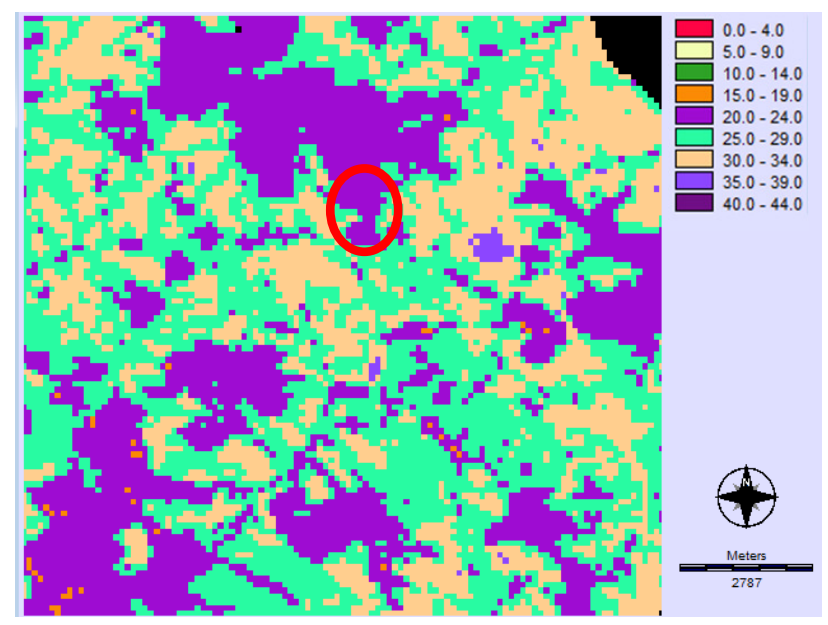

Figura 9 - Classe mata nativa

Na Figura 10 podemos observar a mancha azulada que representa o solo exposto, com temperatura variável entre $35.0^{\circ} \mathrm{C}$ e $39.0^{\circ} \mathrm{C}$, assim como no trabalho realizado por Mashiki (2012), que encontrou valores bem próximos ao citado numa área de solo exposto no Município de Botucatu.

Entre as classes estudadas a classe cultivo de eucalipto e mata nativa apresentaram temperatura aparente amena em torno de $22.0^{\circ} \mathrm{C}$ e o solo exposto onde há maior temperatura aparente este valor apresenta uma média de $37.0^{\circ} \mathrm{C}$. 
Essa temperatura elevada é possível devida a falta de cobertura do solo o que proporciona um aquecimento rápido no período de exposição a radiação solar.

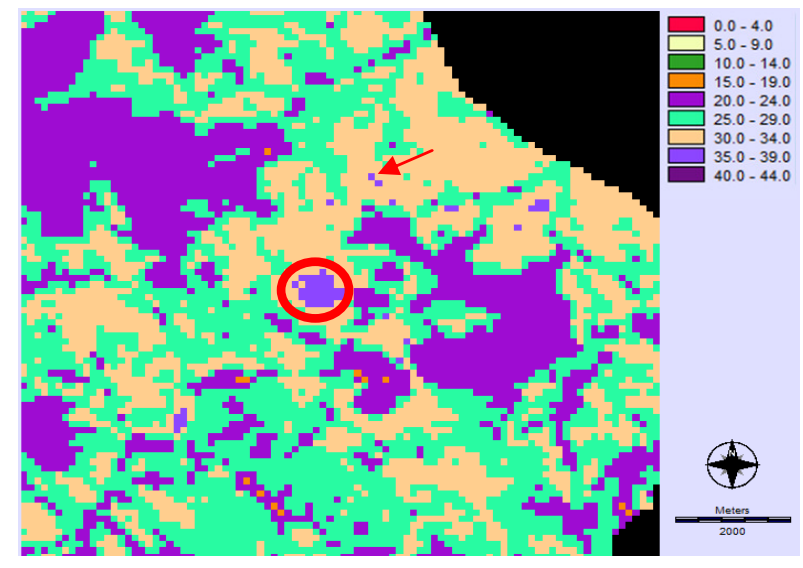

Figura 10 - Classe solo exposto.

\section{CONCLUSÃO}

O sensoriamento remoto e o sistema de informação geográfica permitem a avaliação de diferentes temperaturas da superfície terrestre.

A área reduzida do Município e a baixa resolução do sensor utilizado dificultaram a análise de temperatura da área urbana sendo necessário o uso de outros programas para auxiliar na interpretação de dados.

A cobertura de vegetação na área urbana interfere diretamente na diminuição da temperatura melhorando o micro-clima urbano.

As diferentes coberturas da superfície analisada também interferem na temperatura aparente.

O governo municipal precisa planejar uma forma de ampliação da cobertura verde.

As altas temperaturas do levantamento em campo com termo-higrômetro na área urbana, em média de $35.0^{\circ} \mathrm{C}$ é devido ao clima seco e a ausência de vento além da rugosidade e edificação da superfície.

Com as análises dos resultados recomenda-se que a área de cobertura vegetal seja aumentada e que de forma homogênea ocupe toda a malha urbana.

\section{AGRADECIMENTOS}

Os autores agradecem ao Programa de Pós-Graduação Energia na Agricultura.

\section{REFFERENCIAS}

ALMEIDA, A. L. B. dos S. de S. S. L.. Arvores e floresta urbana: condições que a cidade oferece. In: $\mathbf{O}$ valor das árvores: Arvore e floresta urbana de Lisboa. Tese (Doutorado em arquitetura Paisagista) Instituto Superior de Agronomia. p. 5-45, Lisboa. 2006.

ALMEIDA, D. N. de. Analise da arborização urbana de cinco cidades da região Norte do Estado de Mato
Grosso, 2009. 62 f. Dissertação (Mestrado em Ciências Florestais e Ambientais) - Universidade Federal de Mato Grosso, Cuiabá. 2009.

\section{CEPAGRI - CENTROP DE PESQUISAS} METEOROLÓGICAS E CLIMÁTICAS APLICADAS À AGRICULTURA, 2013. A CLASSIFICAÇÃO CLIMÁTICA DE KOEPPEN PARA O ESTADO DE SÃO PAULO. Disponível em:

$<$ http://www.cpa.unicamp.br/outras-informacoes/climados-municipios-paulistas.html>, acesso em 13 jun 2013.

COLTRI, P.P. Influência do uso e cobertura do solo no clima de Piracicaba, São Paulo: Análise de séries históricas, ilhas de calor e técnicas de sensoriamento remoto. Piracicaba. 2006. 166p. Dissertação (Mestrado em Agronomia/Fitotecnia). Escola Superior de Agronomia Luiz de Queiroz/USP

FERNANDES, N. M. S.; CAMPOS, S.; MOREIRA K. F.; PISSARRA, T. C. T.; RODRIGUES, F. M.; Análise do índice de cobertura vegetal da área urbana de Piratininga (SP), Revista Ciência Geográfica, Bauru, Vol. XV, Jan/Dez. Pág. 78 - 83, 2011.

IBGE - INSTITUTO BRASILEIRO DE GEOGRAFIA E ESTATÍSTICA, 2011. Disponível em Www.censo2010.ibge.gov.br Acesso em 22 nov 2011.

INPE - INSTITUTO NACIONAL DE PESQUISAS ESPACIAIS, 2013. Disponível em www.inpe.br .Acesso em 12 dez 2013.

LOMBARDO, M. A. Ilha de Calor nas metrópoles: o exemplo de São Paulo. São Paulo: Editora Hucitec, 1985. 244p.

MASHIKI, M. Y.; Geoprocessamento na identificação de ilhas de calor e influência do uso e ocupação do solo na temperatura aparente da superfície no município de Botucatu/SP. 2012. 80f. Dissertação (mestrado em Energia na Agricultura). Botucatu, 2013. 